\title{
Chandelier Cells Control Excessive Cortical Excitation: Characteristics of Whisker-Evoked Synaptic Responses of Layer 2/3 Nonpyramidal and Pyramidal Neurons
}

\author{
Yinghua Zhu, ${ }^{1}$ Ruth L. Stornetta, ${ }^{1}$ and J. Julius $\mathrm{Zhu}^{1,2,3}$ \\ ${ }^{1}$ Department of Pharmacology, University of Virginia School of Medicine, Charlottesville, Virginia 22908, ${ }^{2}$ Cold Spring Harbor Laboratory, Cold Spring \\ Harbor, New York 11724, and ${ }^{3}$ Max Planck Institute for Medical Research, Department of Cell Physiology, Heidelberg D-69120, Germany
}

\begin{abstract}
Chandelier cells form inhibitory axo-axonic synapses on pyramidal neurons with their characteristic candlestick-like axonal terminals. The functional role of chandelier cells is still unclear, although the preferential loss of this cell type at epileptic loci suggests a role in epilepsy. Here we report an examination of whisker- and spontaneous activity-evoked responses in chandelier cells and other fast-spiking nonpyramidal neurons and regular-spiking pyramidal neurons in layer $2 / 3$ of the barrel cortex. Fast-spiking nonpyramidal neurons, including chandelier cells, basket cells, neurogliaform cells, double bouquet cells, net basket cells, bitufted cells, and regular-spiking pyramidal neurons all respond to stimulation of multiple whiskers on the contralateral face. Whisker stimulation, however, evokes small, delayed EPSPs preceded by an earlier IPSP and no action potentials in chandelier cells, different from other nonpyramidal and pyramidal neurons. In addition, chandelier cells display a larger receptive field with lower acuity than other fast-spiking nonpyramidal neurons and pyramidal neurons. Notably, simultaneous dual whole-cell in vivo recordings show that chandelier cells, which rarely fire action potentials spontaneously, fire more robustly than other types of cortical neurons when the overall cortical excitation increases. Thus, chandelier cells may not process fast ascending sensory information but instead may be reserved to prevent excessive excitatory activity in neuronal networks.
\end{abstract}

Key words: rat; somatosensory; excitation; inhibition; whisker; epilepsy

\section{Introduction}

Chandelier cells are a unique type of inhibitory neuron that synapses on the axonal initial segment of pyramidal neurons (Szentagothai and Arbib, 1974; Somogyi et al., 1983; Li et al., 1992). Because loss of chandelier cells is commonly and preferentially found at epileptic foci, it is proposed that they are functionally associated with epilepsy (Williams et al., 1977; Ribak, 1985; Freund and Buzsaki, 1988; Marco et al., 1996; Arellano et al., 2004). This view is supported by recent in vivo recordings from two morphologically identified chandelier cells, showing that these cells tend to fire action potentials shortly after synchronized activity of pyramidal neurons (Klausberger et al., 2003). It is unclear, however, whether the loss of chandelier cells represents a consequence of epileptic seizures or a key component that leads to epilepsy, because the functional role of this cell type has not been elucidated (DeFelipe, 1999).

The receptive field properties of cortical neurons have been studied extensively in the last two decades. Some early extracel-

Received Feb. 16, 2004; revised March 30, 2004; accepted April 21, 2004.

This work was supported in part by a University of Virginia Research and Development Award. J.J.Z. is an Alfred P. Sloan Fellow. We thank Drs. Z. Chu, J. Kapur, T. Margrie, and E. Stern and members of the Zhu laboratory for helpful comments and discussions, and Dr. B. Sakmann for his support during the preliminary investigation.

Correspondence should be addressed to J. Julius Zhu, Department of Pharmacology, University of Virginia School of Medicine, 1300 Jefferson Park Avenue, Charlottesville, VA 22908. E-mail: jjzhu@virginia.edu.

DOI:10.1523/JNEUROSCI.0544-04.2004

Copyright $\odot 2004$ Society for Neuroscience $\quad$ 0270-6474/04/245101-08\$15.00/0 lular single-unit recording studies reported small, often singlewhisker receptive fields, whereas others have shown multiplewhisker receptive fields (Simons, 1983; Armstrong-James and Fox, 1987; Ghazanfar and Nicolelis, 1999; Fox et al., 2003). Intracellular recordings with sharp electrodes or whole-cell recordings with patch pipettes have now established that pyramidal and spiny stellate neurons in cortical layers $2-6$ possess a large subthreshold receptive field composed of $\sim 10$ whiskers (Carvell and Simons, 1988; Ito, 1992; Moore and Nelson, 1998; Zhu and Connors, 1999; Stern et al., 2001; Brecht and Sakmann, 2002; Petersen et al., 2003). These studies have also demonstrated that the receptive fields of most excitatory neurons had the same acuity. The average responses in these neurons to the deflection of first-order and second-order surrounding whiskers are $\sim 50 \%$ of those to the deflection of the primary and first-order surrounding whiskers, respectively; however, the receptive field structure of cortical inhibitory interneurons, which represent a significant population of cortical neurons and may participate in various cortical functions (Peters and Jones, 1984; Kawaguchi and Kubota, 1997; Somogyi et al., 1998), is much less understood (Zhu and Connors, 1999; Bruno and Simons, 2002; Swadlow and Gusev, 2002). This is further complicated by recent evidence that distinct inhibitory interneurons may possess different receptive field properties (Hirsch et al., 2003; Zhu and Zhu, 2004).

Using single and simultaneous dual whole-cell in vivo recording techniques, we studied the whisker-evoked synaptic re- 
sponses in fast-spiking (FS) chandelier cells and other FS nonpyramidal and regular-spiking (RS) pyramidal neurons in layer $2 / 3$. We found that chandelier cells responded to whisker stimulation with synaptic events in an IPSP-EPSPs sequence, different from the normal EPSP-IPSP-EPSPs sequence found in all other nonpyramidal and pyramidal neurons, suggesting that chandelier cells may not be involved in processing fast sensory inputs. We also found that in comparison to other FS nonpyramidal and RS pyramidal neurons, chandelier cells generated much more robust firing when local inhibition was partially blocked. These results thus suggest that chandelier cells prevent excessive excitation of the cortical network.

\section{Materials and Methods}

Animal preparation. As described previously (Zhu and Connors, 1999; Larkum and Zhu, 2002), adult rats (180-280 gm) were initially anesthetized by an intraperitoneal injection of pentobarbital sodium $(60 \mathrm{mg} / \mathrm{kg})$. Supplemental doses $(10 \mathrm{mg} / \mathrm{kg})$ of pentobarbital were given as needed to keep animals free from pain reflexes and in a state of slow-wave general anesthesia, as determined by monitoring the cortical electroencephalogram. All pressure points and incised tissues were infiltrated with lidocaine. Body temperature (rectal) was monitored and maintained within the normal range $\left(37.2 \pm 0.3^{\circ} \mathrm{C}\right)$. During the physiological investigation, the animals were placed in a stereotaxic frame. A hole $\sim 3 \times 4 \mathrm{~mm}$ was opened above the right somatosensory cortex according to stereotaxic coordinates. A small chamber was then built around the opening to enable the superperfusion of bicuculline dissolved in oxygenated physiological solution containing (in mM): $125 \mathrm{NaCl}, 2.5 \mathrm{KCl}, 1.25 \mathrm{NaH}_{2} \mathrm{PO}_{4}$, $25 \mathrm{NaHCO}_{3}, 1 \mathrm{MgCl}_{2}, 25$ dextrose, $2 \mathrm{CaCl}_{2}$, pH 7.4 (cf. Margrie et al., 2001). The dura was opened before the electrode penetrations.

Electrophysiology. Whole-cell recordings were made blindly as described in previous reports (Zhu and Connors, 1999; Larkum and Zhu, 2002). Long-taper patch electrodes were made from borosilicate tubing, and their resistances were 5-14 M $\Omega$ when filled with standard intracellular solution containing (in mM): 115 potassium gluconate, 10 HEPES, 2 $\mathrm{MgCl}_{2}, 2 \mathrm{MgATP}, 2 \mathrm{Na}_{2} \mathrm{ATP}, 0.3 \mathrm{GTP}, 20 \mathrm{KCl}$, and biocytin $0.25 \%$, pH 7.3. Liquid junction potential was not corrected. To obtain whole-cell recordings, electrodes were advanced into the brain while pulsing with $0.1 \mathrm{nA}$ current steps of $200 \mathrm{msec}$ duration. Positive pressure (75-150 mbar) was constantly applied to the pipettes while they were being advanced. A short pulse of high pressure (300-450 mbar) was applied intermittently to inject biocytin and stain cell debris along the penetration pathways. When a sudden increase in electrode resistance was evident, gentle suction was applied to obtain a seal resistance of $\geq 1 \mathrm{G} \Omega$. The patches of membranes were broken by applying more negative pressure to obtain a whole-cell configuration. All in vivo data were collected when the access resistance of the recording was $<50 \mathrm{M} \Omega$ using up to two Axoclamp-2B amplifiers (Axon Instruments, Foster City, CA). The electrode capacitance compensation was made in discontinuous currentclamp mode with head-stage outputs monitored continuously on a second oscilloscope.

Whisker stimulation. Single whiskers on the contralateral face were deflected briefly for a short distance $(40-200 \mu \mathrm{m})$ with a piezoelectric stimulator, placed adjacent to the whisker, and activated by single, brief voltage pulses (0.3-0.5 msec, 2-10 V, $0.25 \mathrm{~Hz}$ ) (Dykes et al., 1977; Simons, 1983). To assess the receptive field size of recorded neurons, we examined their responses to a brief deflection of each of 27 mystacial vibrissae, from $A_{0}$ to $E_{5}$, in the contralateral face [whiskers $A_{5}$ and $B_{5}$ were very small and were not stimulated, whereas whisker $E_{0}$ is absent in the rat (Chapin and Lin, 1984)]. Because many cortical cells displayed high rates of spontaneous activity, 8-16 trials of whisker deflection were averaged. The latencies for whisker-evoked EPSPs and IPSPs were measured at the onset of the averaged responses.

Histology. After recordings, a small block of tissue, including the recorded cell(s), was removed from the brain and immersion fixed with $4 \%$ paraformaldehyde in $0.1 \mathrm{~m}$ phosphate buffer. The tissue blocks were later sectioned $250 \mu \mathrm{m}$ thick with a microslicer. Tissue sections were processed with the avidin-biotin-peroxidase method to reveal cell mor- phology. Cells were then drawn with the aid of a microscope equipped with a computerized reconstruction system (Neurolucida, Williston, VT). Only the data from the morphologically identified neurons were included in this report. All results are reported as mean \pm SEM. Statistical differences of the means were determined using Wilcoxon and Mann-Whitney rank sum nonparametric tests for paired and unpaired samples, respectively. The level of significance was set at $p<0.05$.

\section{Results}

\section{Identification of fast-spiking nonpyramidal neurons recorded} in vivo

We examined whisker- and spontaneous activity-evoked responses in nonpyramidal and pyramidal neurons in layer $2 / 3$ of the rat barrel cortex using whole-cell in vivo recording techniques. The classification of these cortical neurons was made after the recovery of their morphology (Fig. 1A,B). Thirty-nine cells generated short-duration action potentials. The firing frequencies of these cells during an episode of repetitive discharges were relatively constant even at high discharge rates, similar to those described previously in vitro (Kawaguchi, 1995; Galarreta and Hestrin, 1999; Gibson et al., 1999; Gupta et al., 2000; Porter et al., 2001). These cells were either bipolar or multipolar aspiny neurons. Among them, 10 neurons had a hallmark axon that gives rise to many candlestick-like axonal terminals, and they were classified as chandelier cells. Chandelier cells and other FS nonpyramidal neurons had the same resting membrane potential $(-64.9 \pm 1.5 \mathrm{mV}, n=10 \mathrm{vs}-65.2 \pm 1.3 \mathrm{mV}, n=29 ; p=0.83)$ and input resistance $(68.1 \pm 6.3 \mathrm{~m} \Omega, n=10$ vs $60.1 \pm 12.5 \mathrm{~m} \Omega$, $n=29 ; p=0.25)$, and they discharged action potentials with the same short duration $(1.23 \pm 0.09 \mathrm{msec}, n=10$ vs $1.32 \pm 0.07$ msec, $n=29 ; p=0.31$ ).

\section{Whisker-evoked responses in fast-spiking nonpyramidal neurons}

A brief deflection of single whiskers on the contralateral face evoked synaptic potentials in all FS nonpyramidal neurons, including 10 chandelier cells (Figs. 1, 2). All FS nonpyramidal neurons, including chandelier cells, responded to multiple surrounding whiskers. Normally one whisker evoked the largest initial EPSP with the shortest latency, and we defined this whisker as the "primary" whisker. In one FS neuron, the shortest latency initial EPSP was evoked by a first-order surrounding whisker; the amplitude of that whisker-evoked EPSP was the second largest in the cell. Unlike other FS neurons (Zhu and Connors, 1999; Margrie et al., 2003; Zhu and Zhu, 2004), chandelier cells responded to whisker stimulation with a small, long-latency initial EPSP followed by several delayed EPSPs (Figs. $1 C, D, 2 A, B$ ). On average, the amplitude of the primary whisker-evoked initial EPSP in chandelier cells was less than half of that in other nonpyramidal FS neurons (Fig. $3 A)(3.8 \pm 0.4 \mathrm{mV}, n=4 \mathrm{vs} 10.7 \pm 1.4 \mathrm{mV}, n=$ $11 ; p<0.01$ ), and the latencies in chandelier cells were $\sim 1-3$ msec longer than those in other FS nonpyramidal neurons (Figs. $1 E, F, 3 B)[(10.3 \pm 0.4 \mathrm{msec}, n=4 \mathrm{vs} 7.5 \pm 0.1 \mathrm{msec}, n=4 ; p<$ 0.01 for primary whisker (PW); $13.0 \pm 0.5 \mathrm{msec}, n=16$ vs $10.1 \pm$ $0.2 \mathrm{msec}, n=41 ; p<0.0001$ for first-order surrounding whisker (1st SW); $14.9 \pm 0.6 \mathrm{msec}, n=11$ vs $13.4 \pm 0.3 \mathrm{msec}, n=20 ; p<$ 0.05 for second-order surrounding whisker (2nd SW)]. The whisker-evoked initial EPSPs in chandelier cells were never large enough to trigger action potentials. Holding these neurons at a depolarized membrane by injecting depolarizing current revealed a whisker-evoked IPSP starting earlier than the initial EPSP (Figs. $1 E, 2 A, C$ ). This was in contrast to other FS nonpyramidal neurons in which the whisker-evoked initial IPSP and 

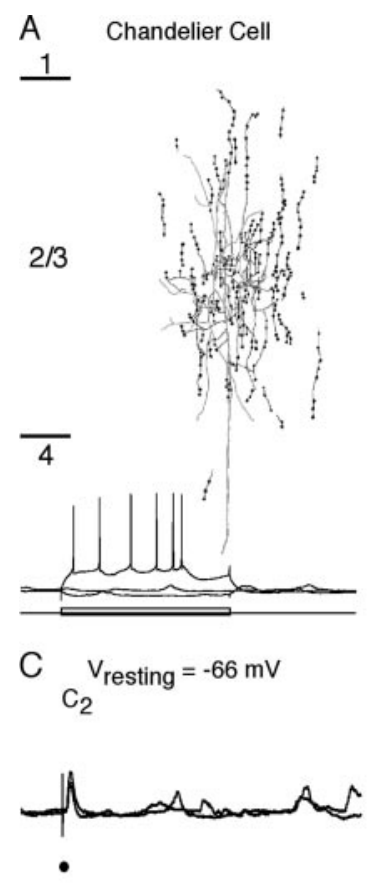

E $\quad V_{\text {holding }}=-56 \mathrm{mV}$
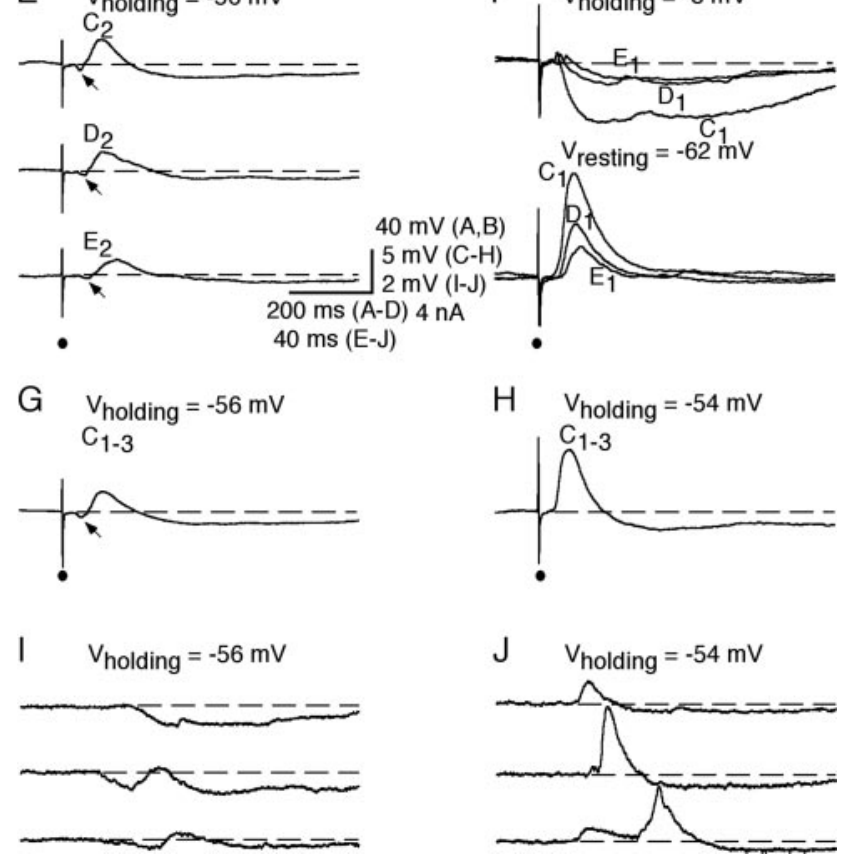

Figure 1. Whisker-evoked synaptic responses in chandelier cells and other $F S$ nonpyramidal neurons. $A, B$, Neurolucida reconstruction of an FS chandelier cell $(A)$ and an FS basket cell ( $B$ ). Recording traces below show responses of the chandelier cell and basket cell to hyperpolarizing and depolarizing current step injections. Short lines on the left side in $A$ and $B$ indicate cortical layer boundaries. $C, D$, Primary whisker-evoked responses of the chandelier cell ( $C$ ) and basket cell $(D)$ at the resting membrane potentials ( 2 single trials). Note that the primary whiskers of the chandelier cell and basket cell were whiskers $C_{2}$ and $C_{1}$, respectively. $E$, $F$, Average responses of the chandelier cell and basket cell to a brief deflection of the primary whisker, a first-order surrounding whisker, and a second-order surrounding whisker. $G, H$, Average responses of the chandelier cell $(G)$ and basket cell $(H)$ to the simultaneous deflection of whiskers $C_{1}, C_{2}$, and $C_{3}$. Note the early IPSPs (arrows) in $E$ and $G . I, J$, Spontaneous events of the chandelier cell $(I)$ and basket cell $(J)$ recorded at slightly depolarized membrane potentials.

several delayed EPSPs followed a whisker-evoked initial EPSP (Figs. $1 F, 2 B, D$ ). Latency analysis revealed that the latencies for the whisker-evoked initial IPSPs were the same in these two groups of FS neurons (Fig. $3 C)(8.2 \pm 0.3 \mathrm{msec}, n=4$ vs $8.9 \pm 0.4$
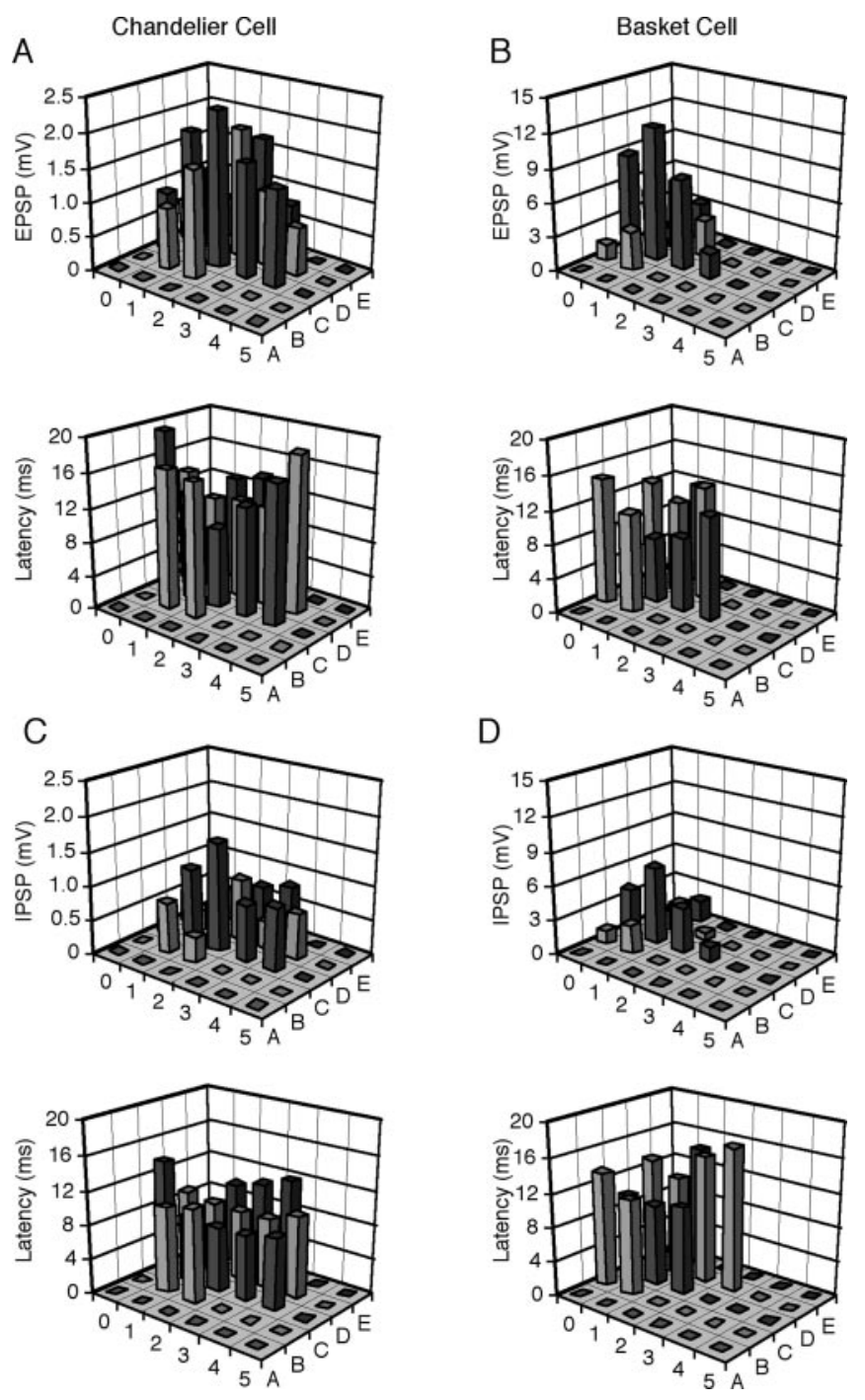

Figure 2. Receptive fields of whisker-evoked synaptic responses of chandelier cells and other FS nonpyramidal neurons. $A, B$, Amplitudes and latency of the initial EPSPs evoked by brief deflections of single whiskers from $A_{0}$ to $E_{5}$ in the chandelier cell $(A)$ and basket cell $(B)$ reconstructed in Figure 1.C, D, Amplitudes and latencies of the initial IPSPs evoked by brief deflections of single whiskers from $\mathrm{A}_{0}$ to $\mathrm{E}_{5}$ in the same chandelier cell ( $C$ ) and basket cell ( $D$ ).

msec, $n=6 ; p=0.17$ for PW; $10.0 \pm 0.4 \mathrm{msec}, n=16$ vs $10.8 \pm$ $0.3 \mathrm{msec}, n=23 ; p=0.36$ for $1 \mathrm{st} \mathrm{SW} ; 12.1 \pm 0.6 \mathrm{msec}, n=11 \mathrm{vs}$ $13.6 \pm 0.7 \mathrm{msec}, n=8 ; p=0.99$ for 2 nd SW). Alteration of the number of whiskers deflected (one to four) (Fig. $1 G, H$ ), as well as whisker stimulus duration $(0.3-10 \mathrm{msec})$, direction $\left(0-360^{\circ}\right)$, and intensity $(2-10 \mathrm{~V})$, had little effect on the whisker-evoked synaptic response patterns in chandelier cells and other FS nonpyramidal neurons, consistent with previous reports that the general pattern of whisker-evoked responses in barrel cortical neurons, particularly FS neurons, was not significantly affected by these stimulus parameters (Brecht and Sakmann, 2002; Bruno and Simons, 2002).

Similar to the evoked responses, spontaneous events displayed similar distinct properties in chandelier cells compared with other FS neurons. When distinguishable from background noise, spontaneous IPSPs were often seen to occur before spontaneous EPSPs in chandelier cells (Fig. 1I). In contrast, spontaneous IPSPs always followed EPSPs in other FS nonpyramidal neurons (Fig. 1J). Thus, chandelier cells do not appear to receive and 
A

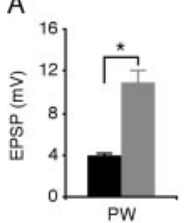

D

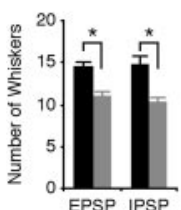

- Chandelier Cells Other FS neurons
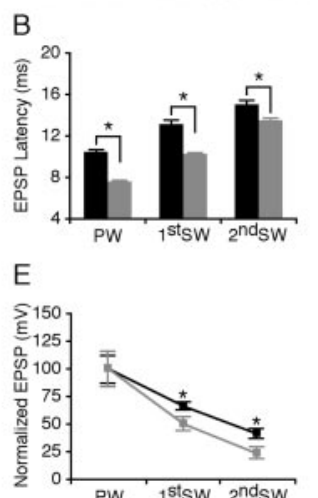

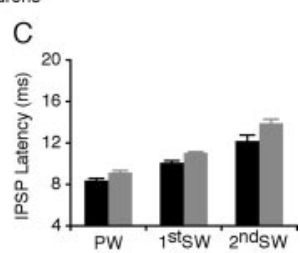

$\mathrm{F}$

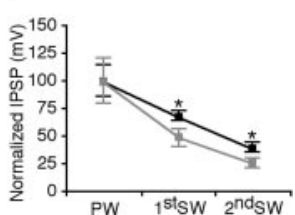

Figure 3. Receptive fields of whisker-evoked synaptic responses of chandelier cells and other FS nonpyramidal neurons. A, Histograms of average amplitudes of the primary whiskerevoked initial EPSPs in chandelier cells (black bars) and other FS nonpyramidal neurons (gray bars). $B$, Histograms of average latencies of the whisker-evoked initial EPSPs of chandelier cells and other FS nonpyramidal neurons. $C$, Histograms of average latencies of the whisker-evoked initial IPSPs of chandelier cells and other FS nonpyramidal neurons. D, Histograms of average excitatory and inhibitory receptive field sizes (defined as the number of whiskers that evoked an initial EPSP or IPSP) for chandelier cells and other FS nonpyramidal neurons. Note that the excitatory and inhibitory receptive field sizes were the same within cell types, although they differed between cell types. E, Plots of average acuities of excitatory receptive fields of chandelier cells and other FS nonpyramidal neurons. F, Plots of average acuities of inhibitory receptive fields of chandelier cells and other FS nonpyramidal neurons. EPSP and IPSP amplitudes and SEs were normalized to average values from primary whiskers.

process the fast ascending sensory information. Instead, the spontaneous and evoked IPSP-EPSP events suggest that chandelier cells are ideal for monitoring the neuronal network excitability and may fire action potentials only when inhibition is reduced and excitation increases, such as when there is excessive excitability or synchronous high-frequency discharges in large groups of excitatory neurons in the network.

To map the receptive field of FS nonpyramidal neurons, we examined their initial excitatory and inhibitory responses to a brief deflection of each of 27 mystacial vibrissae, from $\mathrm{A}_{0}$ to $\mathrm{E}_{5}$, in the contralateral face (see Materials and Methods). For chandelier cells, both whisker-evoked excitatory and inhibitory responses were measured at a slightly depolarized membrane potential. For other FS nonpyramidal neurons, excitatory responses were first measured at the resting membrane potential or a slightly hyperpolarized potential to minimize the effect of IPSPs, whereas inhibitory responses were measured at a depolarized membrane potential $(\sim 5 \mathrm{mV})$ to minimize the effect of initial EPSPs. These tasks succeeded only in a few FS neurons recorded because measurements took $\sim 45-120 \mathrm{~min}$ and many recordings were lost before the measurements were completed, in particular when a continuous depolarizing current was required to be injected to reveal whisker-evoked IPSPs. The receptive field mapping showed that in addition to the primary whisker, $8-15$ surrounding whiskers induced significant initial EPSPs in FS nonpyramidal neurons (Fig. 2). Typically, the same whiskers that evoked an initial EPSP also evoked an IPSP in FS nonpyramidal neurons, and the whisker that evoked the largest EPSP often evoked the largest IPSP (Fig. 2), congruous with previous reports (Brumberg et al., 1996; Moore and Nelson, 1998).

There were obvious differences between receptive field properties of chandelier cells and other FS nonpyramidal neurons. We first assessed the excitatory and inhibitory receptive field sizes, which were defined as the number of whiskers that evoked an initial EPSP or IPSP. Chandelier cells had significantly larger ex-

citatory and inhibitory receptive fields than other FS nonpyramidal neurons (Fig. $3 D)(14.3 \pm 0.9, n=4$ vs $10.9 \pm 0.5, n=11 ; p<$ 0.05 for excitatory receptive field; $14.5 \pm 1.3, n=4$ vs $10.2 \pm 0.6$, $n=6 ; p<0.05$ for inhibitory receptive field). Interestingly, the excitatory and inhibitory receptive fields cover almost exactly the same whiskers in both chandelier cells $(p=0.89)$ and other FS nonpyramidal neurons $(p=0.42)$, similar to the observations made in other cortical areas (Borg-Graham et al., 1998; Wehr and Zador, 2003). Our recent study has shown that inhibitory neurons may have receptive fields with different acuity (Zhu and Zhu, 2004). Plotting amplitudes of whisker-evoked responses against the locations of whiskers in receptive fields revealed that both excitatory $(66.8 \pm 5.7 \%, n=16$ vs $49.2 \pm 3.7 \%, n=41 ; p<$ 0.05 for 1 st SW; $40.5 \pm 4.9 \%, n=11$ vs $23.9 \pm 4.1 \%, n=19 ; p<$ 0.05 for 2 nd SW $)$ and inhibitory $(68.3 \pm 8.2 \%, n=16$ vs $50.1 \pm$ $4.6 \%, n=23$; $t$ test, $p<0.05$ for 1 st SW; $38.7 \pm 4.3 \%, n=11$ vs $24.8 \pm 4.7 \%, n=8$; $t$ test, $p<0.05$ for 2 nd SW) receptive fields of chandelier cells had lower acuities than those of other FS nonpyramidal neurons (Fig. 3 E, F). These results, when compared with recent studies on the receptive fields of other cortical neurons (Moore and Nelson, 1998; Zhu and Connors, 1999; Stern et al., 2001; Brecht and Sakmann, 2002; Brecht et al., 2003; Zhu and Zhu, 2004), suggest that chandelier cells integrate excitatory and inhibitory inputs over a larger area than other cortical neurons. Given that the axo-axonic synapses that chandelier cells form on pyramidal neurons are uniquely designed (Somogyi et al., 1983; Li et al., 1992) and the excitation of chandelier cells is powerful in preventing action potential initiation at the axonal initial segment of pyramidal neurons (Buhl et al., 1994; Miles et al., 1996), these results support the speculation that chandelier cells function to monitor the overall excitability in the cortex and only fire action potentials to dampen excessive excitation.

As reported previously in vitro (Kawaguchi, 1995; Gupta et al., 2000; Porter et al., 2001), we found that in addition to chandelier cells, FS nonpyramidal neurons consisted of subclasses of heterogeneous aspiny neurons with different morphological appearances (Figs. 1, 4). Among those neurons having dendritic and axonal morphology that was well characterized (Figs. 1, 4, 6), we identified neurons with morphological appearances similar to previously described basket cells, neurogliaform cells, double bouquet cells, nest basket cells, and bitufted cells (Kawaguchi, 1995; Kawaguchi and Kubota, 1997; Zhu and Connors, 1999; Gupta et al., 2000; Kaiser et al., 2001; Zhu and Zhu, 2004). All of these cells appeared to respond to whisker stimuli with a similar EPSP-IPSP-EPSPs pattern (Figs. 1, 4D-F) (Zhu and Zhu, 2004); however, larger sample numbers are needed to determine whether there are differences in whisker-evoked response patterns and receptive field properties among these subclasses of nonpyramidal neurons. In this study, we arbitrarily grouped them into a single cell type in the data analysis.

\section{Whisker-evoked responses in regular-spiking pyramidal neurons}

Whisker-evoked synaptic responses of layer $2 / 3$ pyramidal neurons have been well characterized by a recent study (Brecht et al., 2003). As a control, we examined the properties of receptive fields in 16 layer $2 / 3$ pyramidal neurons (Fig. 5 ). The resting membrane potential of these pyramidal neurons was $-75.6 \pm 1.0 \mathrm{mV}(n=$ $16)$, which is more hyperpolarized than chandelier cells $(p<$ $0.0001)$ and other FS nonpyramidal neurons $(p<0.0001)$. The input resistance of these neurons was $50.3 \pm 4.5 \mathrm{~m} \Omega(n=16)$, which is smaller than chandelier cells $(p<0.05)$ but not significantly different from other FS nonpyramidal neurons $(p=0.09)$. 


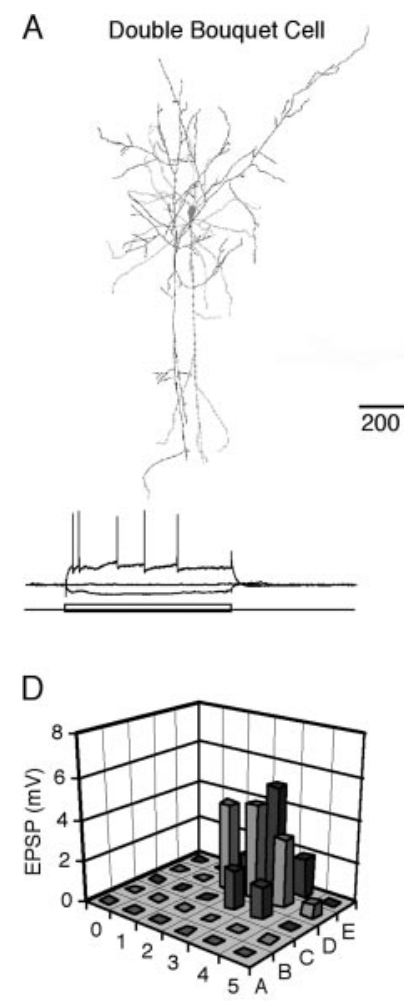

B

Nest Basket Cell
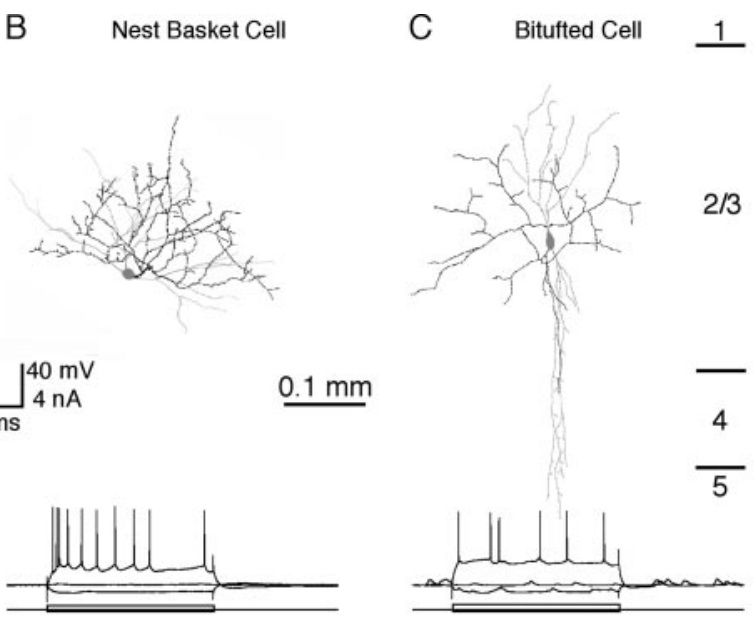

E

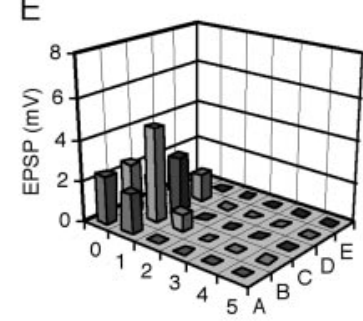

F
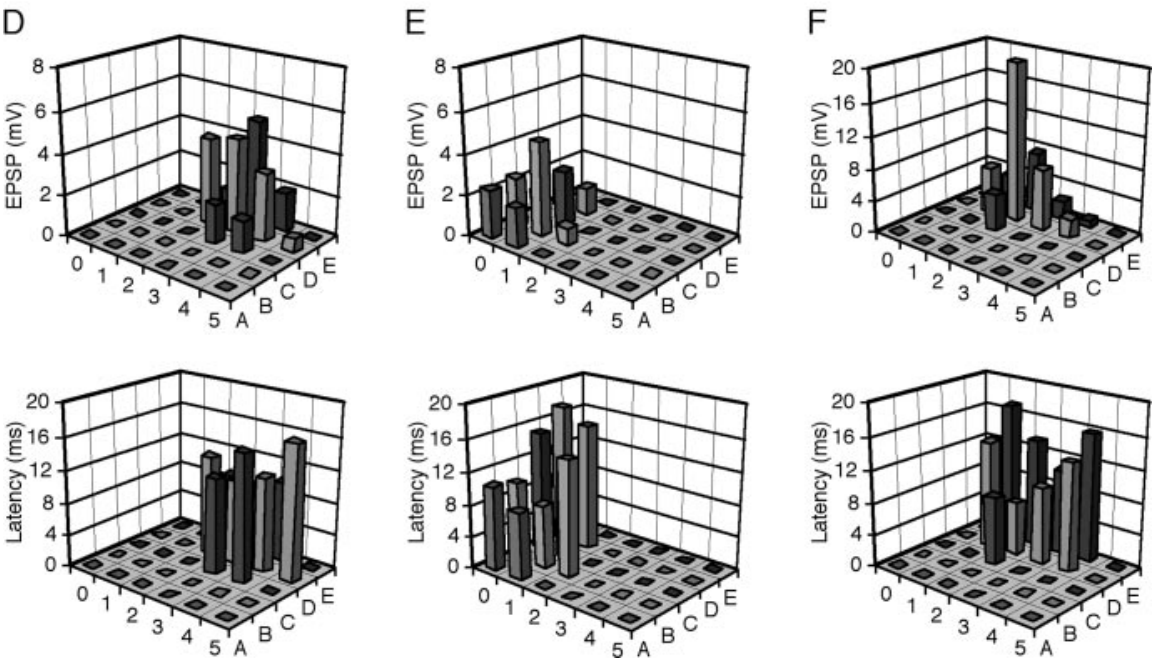

Figure 4. Whisker-evoked synaptic responses in FS nonpyramidal neurons. A-C, Neurolucida reconstruction of a double bouquet cell $(A)$, a net basket cell $(B)$, and a bitufted cell ( $C$. Note that the cell in $A$ has its dendritic and axonal branches vertically oriented, the cell in B exhibits a local net of dendritic and axonal branches on one side of the soma, and the cell in C gives rise to two primary dendrites emerging on opposite sides of the soma. Recording traces below show responses of the nonpyramidal cells to hyperpolarizing and depolarizing current step injections. Cortical layer boundaries indicated by short lines on the right side of $C$ apply to $A-C . D-F$, Amplitudes and latencies of the initial EPSPs evoked by brief deflections of single whiskers from $A_{0}$ to $E_{5}$ in the double bouquet cell $(D)$, net basket cell $(E)$, and bitufted cell $(F)$.

They displayed RS firing patterns with action potential durations $(2.11 \pm 0.13 \mathrm{msec} ; n=16)$ longer than those in chandelier cells $(p<0.0001)$ and other FS nonpyramidal neurons $(p<0.0001)$.

As reported previously (Moore and Nelson, 1998; Zhu and Connors, 1999; Stern et al., 2001; Brecht et al., 2003), layer 2/3 pyramidal neurons responded to multiple whiskers (Fig. $5 B, C$ ). The receptive field size of layer $2 / 3$ pyramidal neurons $(9.9 \pm 0.5$; $n=16)$ was smaller than that of chandelier cells $(p<0.01)$ but the same as that of other FS nonpyramidal neurons $(p=0.21)$. The amplitudes of first-order surrounding whiskers and secondorder surrounding whiskers were $47.1 \pm 3.4 \%(n=41 ; p<0.01)$ and $23.2 \pm 4.0 \%(n=20 ; p<0.01)$ of the primary whiskers, respectively (Fig. $5 D$ ). These responses were the same as those juvenile and adult layer 2/3 neurons (Stern et al., 2001; Brecht et al., 2003), as well as many other barrel neurons reported previously (Zhu and Connors, 1999; Brecht and Sakmann, 2002; Zhu and $\mathrm{Zhu}, 2004)$. These results indicate that the acuity of the receptive field of layer $2 / 3$ pyramidal neurons is significantly smaller than that of chandelier cells (Fig. $5 E)(p<0.01$ for both 1st SW and 2nd SW) but the same as that of other FS nonpyra- midal neurons (Fig. $5 F)(p=0.71$ for 1 st SW; $p=0.83$ for 2 nd SW). These data together support the notion that chandelier cells respond to whisker stimuli differently from other layer 2/3 FS nonpyramidal and RS pyramidal neurons.

\section{Spontaneous action potentials in fast- spiking nonpyramidal neurons}

To investigate when chandelier cells fire action potentials and whether changes of activity in chandelier cells correlate with changes in network excitability, we made simultaneous dual whole-cell in vivo recordings from chandelier cells and other FS nonpyramidal or RS pyramidal neurons (Fig. 6A, $B$ ). We found that in comparison to other cortical neurons, spontaneous events in chandelier cells were smaller in amplitude and rarely triggered action potentials (Fig. $6 B, C$ ). On average, the spontaneous action potential firing rate of chandelier cells was approximately one-sixth of that of other FS nonpyramidal and RS pyramidal neurons $(0.013 \pm 0.002$ vs $0.071 \pm 0.025 \mathrm{~Hz} ; n=8 ; p<0.01)$. We then perfused $2 \mu \mathrm{M}$ bicuculline on the cortical surface above the recordings to disturb the balance of cortical excitation and inhibition. This manipulation caused increases in the amplitude of spontaneous events and firing frequency of both chandelier cells and other FS nonpyramidal and pyramidal neurons, suggesting an overall increase in excitation and decrease in inhibition in the cortex. Remarkably, the increase in the firing frequency of chandelier cells was much larger $(\sim 22$-fold $)$ than that of other cortical neurons $(\sim 1$.6-fold $)$. As a consequence, chandelier cells fired action potentials at a significantly higher rate than other cortical neurons in the presence of bicuculline (Fig. $6 B, C)(0.279 \pm 0.041$ vs $0.116 \pm 0.034 \mathrm{~Hz} ; n=8 ; p<0.01)$. These results indicate that chandelier cells are actively recruited into the cortical circuitry and become more activated than other cortical neurons when the cortex becomes hyperexcited, consistent with the recent in vivo observation that chandelier cells preferentially fire action potentials after the strong, synchronized activity of pyramidal neurons (Klausberger et al., 2003).

\section{Discussion}

In this study, we report that FS chandelier cells and other FS nonpyramidal and RS pyramidal neurons respond to whisker stimulation with distinct synaptic responses. While whisker stimulation evokes small, delayed EPSPs preceded by an earlier IPSP and no action potentials in chandelier cells, it evoked a large, short-latency EPSP followed by an IPSP and several delayed EPSPs and sometimes action potentials in other FS nonpyramidal and RS pyramidal neurons. Although both chandelier cells and other cortical neurons respond to multiple whisker stimulation, chandelier cells have a significantly larger receptive field with lower acuity than other FS nonpyramidal and RS pyramidal neu- 

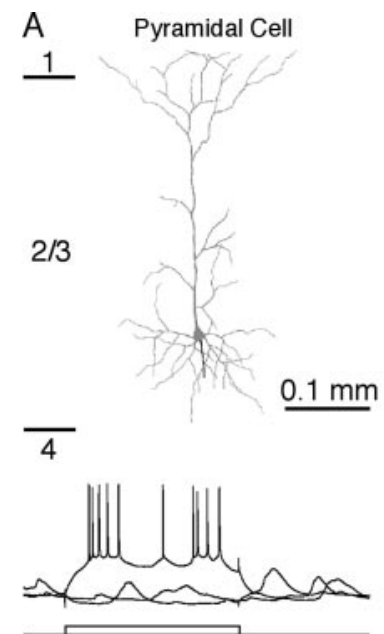

B $V_{\text {resting }}=-62 \mathrm{mV}$
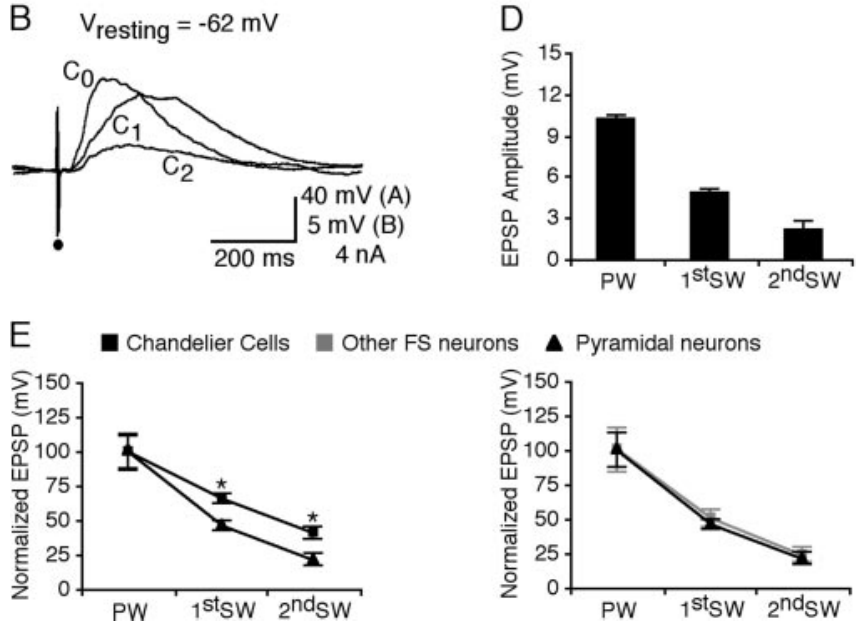

Figure 5. Whisker-evoked synaptic responses in RS pyramidal neurons. A, Neurolucida reconstruction of a layer $2 / 3 \mathrm{RS}$ pyramidal neuron. Recording traces below show responses of the pyramidal cell to hyperpolarizing and depolarizing current step injections. Short lines on the left side indicate cortical layer boundaries. $B$, Average responses of the pyramidal neuron to a brief deflection of the primary whisker $C_{0}$, a first-order surrounding whisker $C_{1}$, and a second-order surrounding whisker $C_{2}$. $C$, Amplitudes and latencies of the initial EPSPs evoked by brief deflections of single whiskers from $\mathrm{A}_{0}$ to $\mathrm{E}_{5}$ in the pyramidal neuron. D, Histograms of average amplitudes of the primary whisker-, first-order surrounding whisker-, and second-order surrounding whisker-evoked initial EPSPs in pyramidal neurons. E, Plots of average acuities of excitatory receptive fields of pyramidal neurons versus chandelier cells (left) and pyramidal neurons versus other FS nonpyramidal neurons (right). EPSP amplitudes and SEs were normalized to average values from primary whiskers.

rons. Thus, it appears that chandelier cells are not involved in coding fast ascending sensory inputs, but instead they are ideal for monitoring overall cortical excitability. Consistent with this idea, chandelier cells rarely fire action potentials in response to spontaneous events, but they fire more robustly than other types of FS nonpyramidal and RS pyramidal neurons when the overall cortical excitation increases, suggesting that they may function to suppress excessive excitation via their powerful inhibitory synapses on pyramidal neurons.

Whisker-evoked responses in chandelier cells and other fastspiking nonpyramidal neurons

Cortical inhibitory interneurons have been classified into many subtypes on the basis of their morphological, anatomical, biochemical, intrinsic, and synaptic properties (Kawaguchi, 1995;
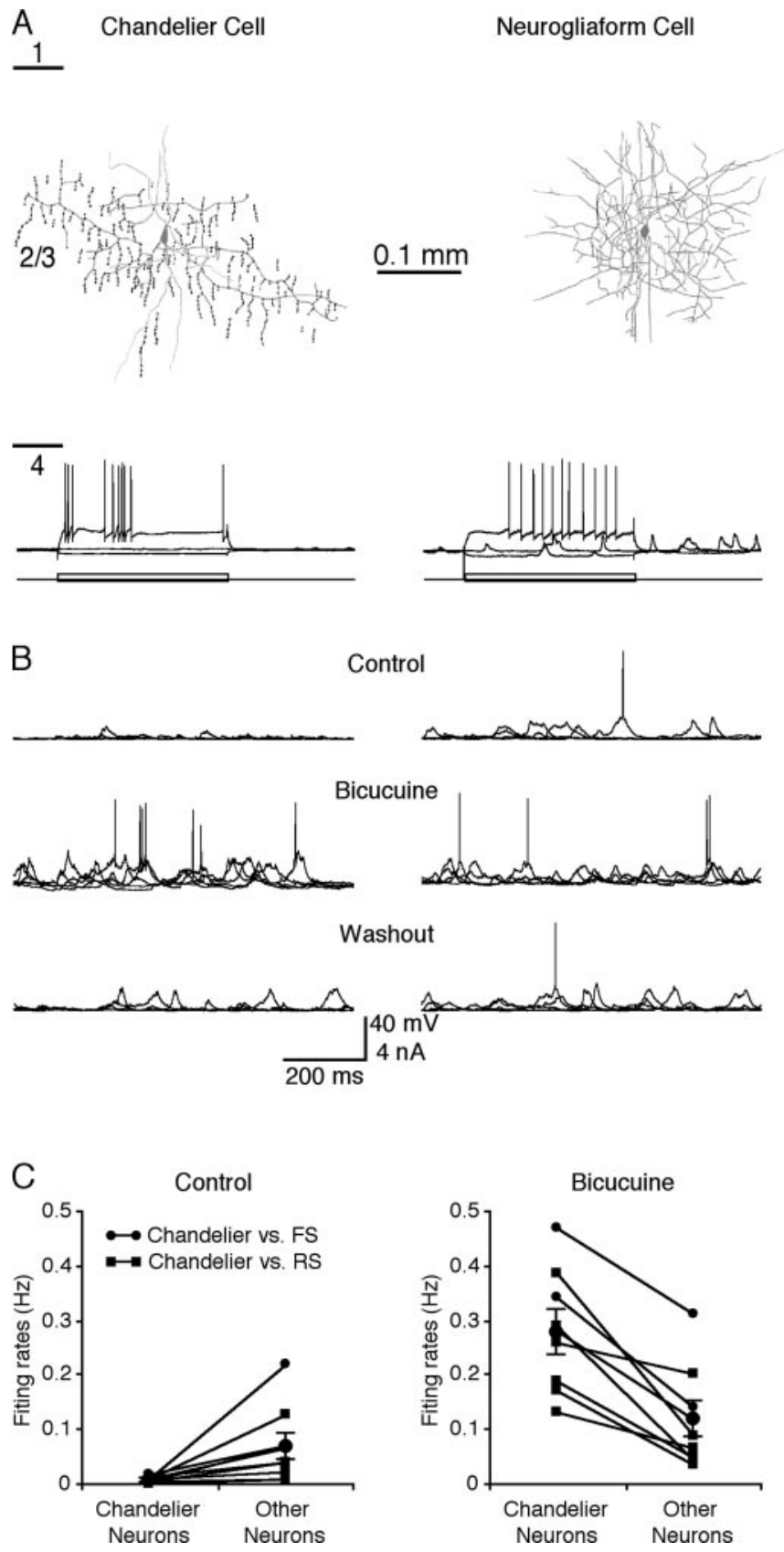

Figure 6. Spontaneous activity-evoked action potentials in simultaneously recorded chandelier cells and other cortical neurons. A, Neurolucida reconstruction of a chandelier cell (left) and a neurogliaform cell (right). Recording traces show the responses of the two neurons to hyperpolarizing and depolarizing current step injections. Short lines on the left side indicate cortical layer boundaries. $B$, Simultaneous recordings of spontaneous activity in the chandelier cell (left) and neurogliaform cell (right) in normal condition (top traces), with superperfusion of $2 \mu \mathrm{m}$ bicuculline (middle traces), or after washout of bicuculline (bottom traces). C, Average spontaneous firing frequency in chandelier cells versus other $\mathrm{FS}$ nonpyramidal or RS pyramidal neurons before and after superperfusion of bicuculline. Note that - indicates chandelier cell and other FS nonpyramidal cell pairs, and - indicates chandelier cell and RS pyramidal cell pairs.

Cauli et al., 2000; Gupta et al., 2000; Karube et al., 2004). Accumulating in vitro and in vitro studies on inhibitory interneurons in the neocortex (Agmon and Connors, 1992; Reyes et al., 1998; Larkum et al., 1999; Beierlein et al., 2000; Galarreta and Hestrin, 2001; Porter et al., 2001; Tamas et al., 2003), as well as those in the hippocampus (Buhl et al., 1994; Miles et al., 1996; Parra et al., 1998; Klausberger et al., 2003) and thalamus (Curro Dossi et al., 
1992; Zhu and Lo, 1998; Cox and Sherman, 2000; Zhu and Heggelund, 2001; Perreault et al., 2003), have now provided compelling evidence that diverse classes of interneurons can generate various forms of inhibitions important for distinct information processes; however, how distinct types of interneurons receive and integrate sensory inputs and how they are functionally different are poorly understood.

Previous extracellular single-unit recordings from putative interneurons, inferred from their short-duration action potential waveforms and bursting firing properties, have suggested that cortical inhibitory interneurons receive synaptic inputs from multiple whiskers (Brumberg et al., 1996; Bruno and Simons, 2002; Swadlow and Gusev, 2002). These studies have also provided the first evidence that whisker stimuli evoke both excitatory and inhibitory inputs in inhibitory interneurons and that the primary whiskers generate the largest excitatory and inhibitory inputs. Recently developed whole-cell recording techniques have made it possible to analyze subthreshold synaptic responses from morphologically identified inhibitory interneurons (Zhu and Connors, 1999; Zhu and Zhu, 2004; Hirsch et al., 2003). Thus, the identity of inhibitory neurons can be unambiguously confirmed after the recordings. Results from these studies indicate that the primary whiskers evoke the largest EPSPs and IPSPs, whereas many surrounding whiskers also generate significant EPSPs and IPSPs in inhibitory interneurons. More importantly, these studies have also demonstrated that distinct types of inhibitory interneurons integrate sensory information differently. For example, our recent work has revealed that although some cortical inhibitory interneurons have the same receptive field with the same acuity as excitatory neurons, others have a smaller receptive field with higher acuity (Zhu and Zhu, 2004). These different receptive field structures are well suited for their different functional roles (Zhu and Zhu, 2004). In the present study, we show that chandelier cells have a larger receptive field with lower acuity than other FS nonpyramidal neurons and RS pyramidal neurons. Because surrounding whisker-evoked responses of barrel cells may be generated primarily by intracortical transmission (Gottlieb and Keller, 1997; Goldreich et al., 1999; Fox et al., 2003), the unique receptive field properties of chandelier cells suggest that these cells receive and integrate excitatory and inhibitory synaptic inputs from a very large cortical area.

Previous extracellular and intracellular recording studies have observed that a whisker-evoked inhibition or IPSP precedes excitation or EPSPs in a small sample of cortical neurons (Hellweg et al., 1977; Moore and Nelson, 1998; Sachdev et al., 2000). It is not clear whether these cells were located in the barrels or septa and what type of cell(s) was recorded in these studies. Here we report that chandelier cells respond to whisker stimuli with synaptic events in an IPSP-EPSPs sequence, different from many other types of morphologically identified layers 1-6 cortical cells that respond to whisker stimulation with synaptic events in an EPSP-IPSP-EPSPs sequence (Ito, 1992; Zhu and Connors, 1999; Brecht and Sakmann, 2002; Brecht et al., 2003; Zhu and Zhu, 2004). Thus, although chandelier cells may receive and integrate excitatory inputs from a large cortical area, whisker-evoked and spontaneous events rarely trigger action potentials in these cells, presumably because of hyperpolarizing and shunting effects of the initial IPSP. It appears that chandelier cells may fire action potentials only when this initial IPSP is reduced. Consistent with this idea, spontaneous EPSPs become much larger and spontaneous firing rate increases dramatically in chandelier cells when the inhibitory tone in the cortex is slightly suppressed with the perfusion of a low concentration of bicuculline on the cortical sur- face. In contrast, the same manipulation only modestly increases the firing rate of other FS nonpyramidal and RS pyramidal neurons. Thus, chandelier cells are particularly sensitive to the balance of cortical excitation and inhibition and switch into a vigorous firing mode when the cortex is hyperexcited.

\section{Functional considerations of chandelier cells}

The origin of epileptic activity is still controversial, and a few conspicuous mechanisms for epileptogenesis (e.g., alternation of neuronal intrinsic properties, general decrease in GABAergic inhibition, and enhancement of excitatory coupling) have been proposed and studied intensively (Prince and Connors, 1986; Prince, 1999). An alternative model for epileptogenesis is that selective loss of chandelier cells, as commonly observed at epileptic foci (Williams et al., 1977; Ribak, 1985; Freund and Buzsaki, 1988; Marco et al., 1996; Arellano et al., 2004), is a crucial event that initiates epileptic activity (DeFelipe, 1999); however, this hypothesis, although intriguing, has not received significant attention because the functional role of chandelier cells in neuronal circuitry is unknown, and it is thus possible that loss of chandelier cells reflects simply a consequence of epileptic activity. Our in vivo results suggest that instead of being involved in processing and coding fast sensory information, chandelier cells may be reserved to oversee the balance of excitatory and inhibitory inputs over a large cortical area, and these cells increase their firing rate dramatically when excitation overpowers inhibition. Because action potentials from chandelier cells are extremely powerful in suppressing action potential initiation in pyramidal neurons (Buhl et al., 1994; Miles et al., 1996), chandelier cells may function as the last defense to keep network excitability from going out of control. Loss of chandelier cells, which makes the neuronal network incapable of dampening excessive excitation resulting from other causes of epileptogenesis (Wong and Prince, 1979; Connors, 1984; Cohen et al., 2002), may be one of the key events leading to epilepsy.

\section{References}

Agmon A, Connors BW (1992) Correlation between intrinsic firing patterns and thalamocortical synaptic responses of neurons in mouse barrel cortex. J Neurosci 12:319-329.

Arellano JI, Munoz A, Ballesteros-Yanez I, Sola RG, DeFelipe J (2004) Histopathology and reorganization of chandelier cells in the human epileptic sclerotic hippocampus. Brain 127:45-64.

Armstrong-James M, Fox K (1987) Spatiotemporal convergence and divergence in the rat S1 "barrel" cortex. J Comp Neurol 263:265-281.

Beierlein M, Gibson JR, Connors BW (2000) A network of electrically coupled interneurons drives synchronized inhibition in neocortex. Nat Neurosci 3:904-910.

Borg-Graham LJ, Monier C, Fregnac Y (1998) Visual input evokes transient and strong shunting inhibition in visual cortical neurons. Nature 393:369-373.

Brecht M, Sakmann B (2002) Dynamic representation of whisker deflection by synaptic potentials in spiny stellate and pyramidal cells in the barrels and septa of layer 4 rat somatosensory cortex. J Physiol (Lond) 543:49-70.

Brecht M, Roth A, Sakmann B (2003) Dynamic receptive fields of reconstructed pyramidal cells in layers 3 and 2 of rat somatosensory barrel cortex. J Physiol (Lond) 553:243-265.

Brumberg JC, Pinto DJ, Simons DJ (1996) Spatial gradients and inhibitory summation in the rat whisker barrel system. J Neurophysiol 76:130-140.

Bruno RM, Simons DJ (2002) Feedforward mechanisms of excitatory and inhibitory cortical receptive fields. J Neurosci 22:10966-10975.

Buhl EH, Halasy K, Somogyi P (1994) Diverse sources of hippocampal unitary inhibitory postsynaptic potentials and the number of synaptic release sites. Nature 368:823-828.

Carvell GE, Simons DJ (1988) Membrane potential changes in rat SmI cortical neurons evoked by controlled stimulation of mystacial vibrissae. Brain Res 448:186-191. 
Cauli B, Porter JT, Tsuzuki K, Lambolez B, Rossier J, Quenet B, Audinat E (2000) Classification of fusiform neocortical interneurons based on unsupervised clustering. Proc Natl Acad Sci USA 97:6144-6149.

Chapin JK, Lin CS (1984) Mapping the body representation in the SI cortex of anesthetized and awake rats. J Comp Neurol 229:199-213.

Cohen I, Navarro V, Clemenceau S, Baulac M, Miles R (2002) On the origin of interictal activity in human temporal lobe epilepsy in vitro. Science 298:1418-1421.

Connors BW (1984) Initiation of synchronized neuronal bursting in neocortex. Nature 310:685-687.

Cox CL, Sherman SM (2000) Control of dendritic outputs of inhibitory interneurons in the lateral geniculate nucleus. Neuron 27:597-610.

Curro Dossi R, Pare D, Steriade M (1992) Various types of inhibitory postsynaptic potentials in anterior thalamic cells are differentially altered by stimulation of laterodorsal tegmental cholinergic nucleus. Neuroscience 47:279-289.

DeFelipe J (1999) Chandelier cells and epilepsy. Brain 122:1807-1822.

Dykes RW, Dudar JD, Tanji DG, Publicover NG (1977) Somatotopic projections of mystacial vibrissae on cerebral cortex of cats. J Neurophysiol 40:997-1014.

Fox K, Wright N, Wallace H, GlazewskiS (2003) The origin of cortical surround receptive fields studied in the barrel cortex. J Neurosci 23:8380-8391.

Freund TF, Buzsaki G (1988) Alterations in excitatory and GABAergic inhibitory connections in hippocampal transplants. Neuroscience 27:373-385.

Galarreta M, Hestrin S (1999) A network of fast-spiking cells in the neocortex connected by electrical synapses. Nature 402:72-75.

Galarreta M, Hestrin S (2001) Spike transmission and synchrony detection in networks of GABAergic interneurons. Science 292:2295-2299.

Ghazanfar AA, Nicolelis MA (1999) Spatiotemporal properties of layer V neurons of the rat primary somatosensory cortex. Cereb Cortex 9:348-361.

Gibson JR, Beierlein M, Connors BW (1999) Two networks of electrically coupled inhibitory neurons in neocortex. Nature 402:75-79.

Goldreich D, Kyriazi HT, Simons DJ (1999) Functional independence of layer IV barrels in rodent somatosensory cortex. J Neurophysiol 82:1311-1316.

Gottlieb JP, Keller A (1997) Intrinsic circuitry and physiological properties of pyramidal neurons in rat barrel cortex. Exp Brain Res 115:47-60.

Gupta A, Wang Y, Markram H (2000) Organizing principles for a diversity of GABAergic interneurons and synapses in the neocortex. Science 287:273-278

Hellweg FC, Schultz W, Creutzfeldt OD (1977) Extracellular and intracellular recordings from cat's cortical whisker projection area: thalamocortical response transformation. J Neurophysiol 40:463-479.

Hirsch JA, Martinez LM, Pillai C, Alonso JM, Wang Q, Sommer FT (2003) Functionally distinct inhibitory neurons at the first stage of visual cortical processing. Nat Neurosci 6:1300-1308.

Ito M (1992) Simultaneous visualization of cortical barrels and horseradish peroxidase-injected layer $5 \mathrm{~b}$ vibrissa neurones in the rat. J Physiol (Lond) 454:247-265.

Kaiser KM, Zilberter Y, Sakmann B (2001) Back-propagating action potentials mediate calcium signaling in dendrites of bitufted interneurons in layer 2/3 of rat somatosensory cortex. J Physiol (Lond) 535:17-31.

Karube F, Kubota Y, Kawaguchi Y (2004) Axon branching and synaptic bouton phenotypes in GABAergic nonpyramidal cell subtypes. J Neurosci 24:2853-2865.

Kawaguchi Y (1995) Physiological subgroups of nonpyramidal cells with specific morphological characteristics in layer II/III of rat frontal cortex. J Neurosci 15:2638-2655.

Kawaguchi Y, Kubota Y (1997) GABAergic cell subtypes and their synaptic connections in rat frontal cortex. Cereb Cortex 7:476-486.

Klausberger T, Magill PJ, Marton LF, Roberts JD, Cobden PM, Buzsaki G, Somogyi P (2003) Brain-state- and cell-type-specific firing of hippocampal interneurons in vivo. Nature 421:844-848.

Larkum ME, Zhu JJ (2002) Signaling of layer 1 and whisker-evoked $\mathrm{Ca}^{2+}$ and $\mathrm{Na}^{+}$action potentials in distal and terminal dendrites of rat neocortical pyramidal neurons in vitro and in vivo. J Neurosci 22:6991-7005.

Larkum ME, Zhu JJ, Sakmann B (1999) A new cellular mechanism for coupling inputs arriving at different cortical layers. Nature 398:338-341.

Li XG, Somogyi P, Tepper JM, Buzsaki G (1992) Axonal and dendritic arborization of an intracellularly labeled chandelier cell in the CA1 region of rat hippocampus. Exp Brain Res 90:519-525.

Marco P, Sola RG, Pulido P, Alijarde MT, Sanchez A, Ramon y Cajal S,
DeFelipe J (1996) Inhibitory neurons in the human epileptogenic temporal neocortex. An immunocytochemical study. Brain 119:1327-1347.

Margrie TW, Sakmann B, Urban NN (2001) Action potential propagation in mitral cell lateral dendrites is decremental and controls recurrent and lateral inhibition in the mammalian olfactory bulb. Proc Natl Acad Sci USA 98:319-324.

Margrie TW, Meyer AH, Caputi A, Monyer H, Hasan MT, Schaefer AT, Denk W, Brecht M (2003) Targeted whole-cell recordings in the mammalian brain in vivo. Neuron 39:911-918.

Miles R, Toth K, Gulyas AI, Hajos N, Freund TF (1996) Differences between somatic and dendritic inhibition in the hippocampus. Neuron 16:815-823.

Moore CI, Nelson SB (1998) Spatio-temporal subthreshold receptive fields in the vibrissa representation of rat primary somatosensory cortex. J Neurophysiol 80:2882-2892.

Parra P, Gulyas AI, Miles R (1998) How many subtypes of inhibitory cells in the hippocampus? Neuron 20:983-993.

Perreault MC, Qin Y, Heggelund P, Zhu JJ (2003) Postnatal development of GABAergic signaling in the rat lateral geniculate nucleus: presynaptic dendritic mechanisms. J Physiol (Lond) 546:137-148.

Peters A, Jones EG (1984) Cerebral cortex. New York: Plenum.

Petersen CC, Hahn TT, Mehta M, Grinvald A, Sakmann B (2003) Interaction of sensory responses with spontaneous depolarization in layer $2 / 3$ barrel cortex. Proc Natl Acad Sci USA 100:13638-13643.

Porter JT, Johnson CK, Agmon A (2001) Diverse types of interneurons generate thalamus-evoked feedforward inhibition in the mouse barrel cortex. J Neurosci 21:2699-2710.

Prince DA (1999) Epileptogenic neurons and circuits. Adv Neurol 79:665-684. Prince DA, Connors BW (1986) Mechanisms of interictal epileptogenesis. Adv Neurol 44:275-299.

Reyes A, Lujan R, Rozov A, Burnashev N, Somogyi P, Sakmann B (1998) Target-cell-specific facilitation and depression in neocortical circuits. Nat Neurosci 1:279-285.

Ribak CE (1985) Axon terminals of GABAergic chandelier cells are lost at epileptic foci. Brain Res 326:251-260.

Sachdev RN, Sellien H, Ebner FF (2000) Direct inhibition evoked by whisker stimulation in somatic sensory (SI) barrel field cortex of the awake rat. J Neurophysiol 84:1497-1504.

Simons DJ (1983) Multi-whisker stimulation and its effects on vibrissa units in rat SmI barrel cortex. Brain Res 276:178-182.

Somogyi P, Nunzi MG, Gorio A, Smith AD (1983) A new type of specific interneuron in the monkey hippocampus forming synapses exclusively with the axon initial segments of pyramidal cells. Brain Res 259:137-142.

Somogyi P, Tamas G, Lujan R, Buhl EH (1998) Salient features of synaptic organisation in the cerebral cortex. Brain Res Brain Res Rev 26:113-135.

Stern EA, Maravall M, Svoboda K (2001) Rapid development and plasticity of layer 2/3 maps in rat barrel cortex in vivo. Neuron 31:305-315.

Swadlow HA, Gusev AG (2002) Receptive-field construction in cortical inhibitory interneurons. Nat Neurosci 5:403-404.

Szentagothai J, Arbib MA (1974) Conceptual models of neural organization. Neurosci Res Program Bull 12:305-510.

Tamas G, Lorincz A, Simon A, Szabadics J (2003) Identified sources and targets of slow inhibition in the neocortex. Science 299:1902-1905.

Wehr M,Zador AM (2003) Balanced inhibition underlies tuning and sharpens spike timing in auditory cortex. Nature 426:442-446.

Williams RS, Lott IT, Ferrante RJ, Caviness VS Jr (1977) The cellular pathology of neuronal ceroid-lipofuscinosis. A Golgi-electron microscopic study. Arch Neurol 34:298-305.

Wong RK, Prince DA (1979) Dendritic mechanisms underlying penicillininduced epileptiform activity. Science 204:1228-1231.

Zhu JJ, Connors BW (1999) Intrinsic firing patterns and whisker-evoked synaptic responses of neurons in the rat barrel cortex. J Neurophysiol 81:1171-1183.

Zhu JJ, Heggelund P (2001) Muscarinic regulation of dendritic and axonal outputs of rat thalamic interneurons: a new cellular mechanism for uncoupling distal dendrites. J Neurosci 21:1148-1159.

Zhu JJ, Lo FS (1998) Control of recurrent inhibition of the lateral posteriorpulvinar complex by afferents from the deep layers of the superior colliculus of the rabbit. J Neurophysiol 80:1122-1131.

Zhu Y, Zhu JJ (2004) Rapid arrival and integration of ascending sensory information in layer 1 nonpyramidal neurons and tuft dendrites of layer 5 pyramidal neurons of the neocortex. J Neurosci 24:1272-1279. 